\title{
Is it assessment of learning or assessment for learning?
}

\author{
Sayeeda Rahman ${ }^{1}$, Md. Anwarul Azim Majumder ${ }^{2}$
}

${ }^{1,2}$ Lecturer, Department of Clinical Sciences, School of Medical Sciences, University of Bradford, Bradford BD7 1DP, UK.

Assessment is a central feature of teaching and the curriculum. It powerfully frames how students learn and what students achieve. It is one of the most significant influences on students' experience of higher education and all that they gain from it. The reason for an explicit focus on improving assessment practice is the huge impact it has on the quality of learning'.

\section{'Students should realize that assessment can be an opportunity for learning, rather than just something to be endured and suffered'.}

\section{'Institutions should ensure that appropriate feedback is provided to students on assessed work in a way that promotes learning and facilitates improvement.$^{3}$}

Assessment is one of the most powerful educational tools for promoting effective student learning. ${ }^{2,4}$ It is probably the most important thing teachers can do to help their students learn. ${ }^{5}$ Assessment is a vital part of the all modern medical curricula and it provides the means for ensuring competence, quality, providing guidance and feedback. ${ }^{6}$ Medical schools use different forms of assessment to examine the students' knowledge, skills, attitudes and abilities so that patient safety is maintained when they become doctors later in their professional life. ${ }^{6,7}$

Teachers need to consider a number of factors while designing assessment techniques for students. Miller ${ }^{8}$ developed a framework for different levels of assessment and it is essential that medical schools should assess students at all levels using different forms of assessment. The pyramid in Fig 1 has two halves: cognitive levels (bottom two sections) and behavioral levels (top two sections). Other factors which need to be considered in designing assessment include: reliability, validity, feasibility and educational impact. ${ }^{9}$

Assessment is a part of the learning process and should be learner-centered and practice-orientated. ${ }^{2}$ An assessment needs to be 'fit-for-purpose' which should enable evaluation of the extent to which learners have learned and the extent to which they can demonstrate that learning. ${ }^{1}$ Teachers need to consider not just what they are assessing and how they are doing it, but also why rationale for assessing on any particular occasion and in any context. ${ }^{2}$

The most pertinent question: 'Is it assessment of learning or assessment for learning'? A clear distinction should be made between assessment of learning and assessment for learning. ${ }^{2}$ The first one is traditional exams, used in most of the medical schools for the purposes of grading and reporting. However, the latter calls for different priorities and new procedures to encourage and enhance students' learning. ${ }^{2}$ For assessment of learning, summative, feed -out, or high-stakes assessment are used and the goal is to evaluate student learning at the end of an instructional unit by comparing it against some standard or benchmark. ${ }^{10}$ A recent report published by the General Medical Council (UK) mentioned that a greater proportion of exams are high stakes or hurdle exams, or both in some of the medical schools in the UK. ${ }^{6}$ The medical schools in Southeast Asia are also heavily reliant on traditional assessment systems (used very long exams, or essay questions) $)^{11,12}$ - which is criticized as 'untenable' and 'dubious' assessment practices. ${ }^{13}$ It is arguable that assessment in medical education is too often focussed on the summative assessment, while students would benefit from feedback staged throughout their course or module i.e. formative feedback. ${ }^{14}$ Teachers should have clear idea to distinguish between assessment which is mainly intended to help the student learn and assessment intended to identify how much has been learnt.

Assessment for learning has now become an internationally accepted term in higher education and becomes part of the teaching learning strategies in many academic institutions. ${ }^{2}$ It aims to provide ongoing feedback on their performance and on how it can be improved and/or maintained. Sambell et al. ${ }^{2}$ proposed a holistic model of assessment for learning which 'represents an overall approach to assessment, rather than a set of techniques' for the teachers and student to adopt. The six principles of the model are as follows:

\begin{abstract}
Designing authentic assessment
Assessment contents/methods should be designed to promote deep, complex and worthwhile learning rather than reproduction of knowledge and reductive measurement. Assessment should help students to develop a sense of 'really doing' the subject and offer students a sense of personal involvement.
\end{abstract}

Correspondence: Dr Sayeeda Rahman, Lecturer, Department of Clinical Sciences, School of Medical Sciences, University of Bradford, Bradford BD7 1DP, UK. Email: srahman6@bradford.ac.uk. 


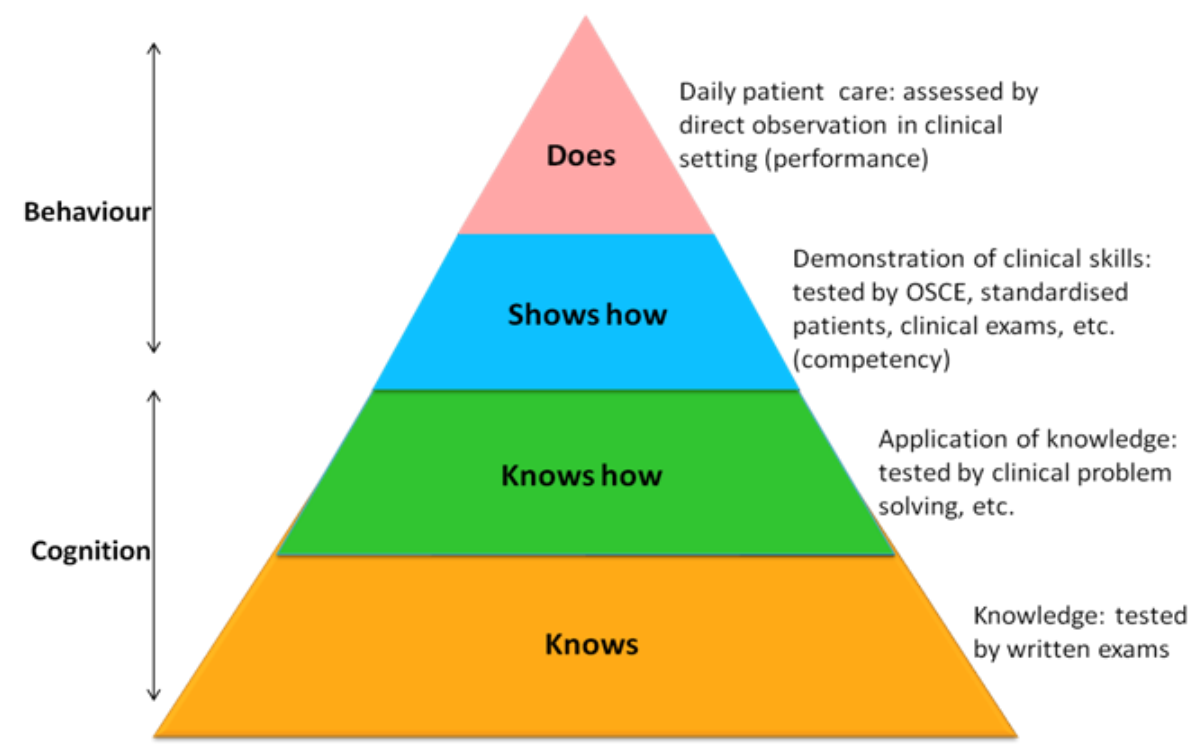

Fig. 1: Miller's assessment pyramid ${ }^{8}$

\begin{abstract}
Appropriate balancing of summative and formative assessment

Summative as well as formative assessment should be a source of learning. Summative assessment should not drive the whole of the teaching, learning and assessment process. Formative assessment should be designed to encourage student engagement with genuine learning through all phases of the curriculum.
\end{abstract}

- Creating confidence-building opportunities for practice and rehearsal

Students should be able to try out their learning and practice, and improve competence before they are summatively assessed.

\section{- Designing formal feedback to improve learning}

The course/curricula should be designed to promote practice and rehearsal, gradual development, active involvement, effective formative assessment environments and learning communities. Well-designed and planned feedforward and tutor, self and peer feedback should be provided for effective students' learning.

- Designing opportunities for informal feedback Providing informal feedback to enhance learning through classroom dialogue, encouraging students to work collaboratively, and seeding activity and dialogue beyond the classroom.

Developing students as self-assessors and effective lifelong learners

There should be opportunities for students to be active participants in assessment processes and develop assessment literacy by enabling them to better appreciate the standards, goals and criteria required to evaluate educational outcome.
Careful design of the assessment strategy is crucial in determining the quality and amount of learning achieved by students in medical schools. ${ }^{6,7}$ In the present medical curricula, much emphasis is given on summative assessment (assessment of learning), which can potentially limit a student's broader learning and independent thinking. It should be noted that summative assessment has important purposes in selection, certification, and institutional standard and accountability, which should not be undermined or ignored. ${ }^{9,15}$ However, assessment for learning should be designed to be formative and diagnostic which should provide information about student's achievement to both teachers and learners, and respond to the needs of the learner. ${ }^{1,2}$ This benefit is enhanced where feedback is embedded in day-to-day learning activities, and ultimately develops learning and skills essential for professional life and lifelong learning. ${ }^{16}$

Another issue that needs important consideration is the assessment method and approach, which needs to be focused on evidence of achievement rather than the ability to regurgitate information. ${ }^{7}$ Medical schools should put lesser attention on traditional written assessments, particularly time-constrained unseen exams, and a greater emphasis on assessment instruments that measure not just recall of facts, but developing desired competencies needed for future professional life. ${ }^{17}$ Rather than using traditional exam formats, teachers could consider using innovative assessment methods that are now widely used in medical education internationally e.g. portfolios, reflective commentaries/writings, critical incident accounts, reviews, role-plays, real case studies, OSCEs/ OSPEs, MCQs/EMQs (paper and computer-based), posters and presentations (individual and groups), individual projects, open-book exams, learning contracts, Constructed Response Questions (CRQs), MiniClinical Evaluation Exercise (Mini-CEX), Direct Observation of Procedural Skills (DOPS), simulations etc. ${ }^{1,6,7,9}$ It is also important to consider who should 
carry out the assessment. For example, tutors, peers, employers, clinical supervisors, patients, and even the student themselves can be involved in assessment which would provide a better understanding of how students engage in different situations. ${ }^{16}$

In South-East Asia, medical schools usually practice assessment of learning and use mostly traditional assessment methods which are not at all consistent with the innovative approaches of curriculum planning. ${ }^{18,19}$ The medical educators in the region should seriously consider integrating assessment fully into the curriculum to ensure that assessment is for, and not just $o f$, learning. ${ }^{20}$ The assessment strategy, policy and practice require radical reshaping based on evidenceinformed medical education research. ${ }^{12}$ Assessment should focus on improved potential for student learning, increased student satisfaction, improved value for money (increasing efficiency), attainment of the outcomes required for 21 st century doctors; and finally, setting academic standards for medical education. ${ }^{13,19-21}$ For effective change towards assessment for learning, we require academic leadership; students' awareness, involvement and motivation; resource management; faculty development and motivation; relevant policy and regulations; and finally adaptation of technologyenhanced and culturally-relevant assessment strategies.

\section{References}

1. Boud D and Associates. Assessment 2020: Seven propositions for assessment reform in higher education. Sydney: Australian Learning and Teaching Council, 2010.

2. Sambell K, McDowell L, Montgomery C. Assessment for Learning in Higher Education. Abingdon: Routledge, 2013.

3. QAA. Understanding assessment: its role in safeguarding academic standards and quality in higher education: A guide for early career staff. Gloucester: The Quality Assurance Agency for Higher Education, 2012

4. Brown B. Assessment for Learning. Learn Teach Higher Educ 2004-05;1:81-9.

5. Biggs, J. Teaching for quality learning at university. Second edition. Buckingham: SRHE \& Open University Press, 2003.

6. General Medical Council. How are students assessed at medical schools across the UK? London: GMC, 2014.

7. Tabish SA. Assessment Methods in Medical Education. Int J Health Sci (Qassim) 2008;2(2): 3-7.
8. Miller GE. The assessment of clinical skills/ competence/ performance. Acad Med 1990;65(9 Suppl):S63-7.

9. Brown, G., Bull, J. Pendlebury, M. Assessing student learning in higher education. London; Routledge, 1997.

10. Knight, Peter T. Summative assessment in Higher Education: practices in disarray. Stud Higher Educ 2002; 27(3):275-86.

11. Sood R. Medical education in India. Med Teach 2008;30:585-91.

12. Majumder MAA. Issues and Priorities of Medical Education Research in Asia. Ann Acad Med Singapore 2004;33:257-63.

13. Amin Z, Burdick WP, Supe A, Singh T. Relevance of the Flexner Report to contemporary medical education in South Asia. Acad Med 2010;85(2):333-9.

14. Rust C. Purposes and principles of assessment. Learning and Teaching Briefing Papers Series. Oxford Centre for Staff and Learning Development. Oxford: Oxford Brookes University, 2002.

15. Brown S, Glasner A (eds.) Assessment Matters in Higher Education: Choosing and Using Diverse Approaches. Buckingham: SRHE and Open University Press, 1999.

16. Sambell K. Rethinking feedback in higher education: an assessment for learning perspective. Discussion paper. ESCalate: HEA Subject Centre for Education, Bristol, 2011.

17. General Medical Council (GMC). Tomorrow's doctors. London: GMC, 2009.

18. Majumder MAA. A review of the undergraduate medical curriculum in Bangladesh. Bangladesh Med J 2002;31:47-9.

19. Amin Z, Hoon Eng K, Gwee M, Dow Rhoon K, Chay Hoon T. Medical education in Southeast Asia: emerging issues, challenges and opportunities. Med Educ 2005: 39(8):829-32.

20. Majumder MAA, D'Souza U, Rahman S. Trends in Medical Education: Challenges and Directions for Need-based Reforms of Medical Training in South-East Asia. Indian J Med Sci 2004;58(9):369-80.

21. Majumder MAA. How can we teach students if we do not know how they learn? South Asia J Public Health 2013:3:70-3. 